\title{
A NOTE ON THE 1976, GAZLI ACCELEROGRAM
}

\author{
J. B. Berrill*
}

The high peak accelerations recorded at Karakyr Point during the $\mathrm{M}_{\mathrm{S}}=7.2$ May 17 , 1976 Gazli, U.S.S.R. earthquake have caused considerable interest amongst earthquake engineers particularly in this country where aseismic design of structures is currently based on the $\mathrm{N}-\mathrm{S}$ component of the $\mathrm{M}_{\mathrm{S}}=7.1$ May 18, 1940 El Centro, California accelerogram with much lower peak accelerations. Information about the Gazli earthquake is quite scanty. However, because of the interest it has generated it is felt that in spite of the limited information available a preliminary discussion of the record would be useful.

The location of the Karakyr Point strong motion accelerograph, which was part of a temporary network installed after a $M_{S}=7.0$ shock in the region on April 8, 1976, is shown in Figure 1 which is taken from reference (1). The instrument site was $10 \mathrm{~km}$ from the May 17th epicentre and if either of the probable fault plane locations shown in Figure 1 is correct, the accelerograph site was within two to three kilometers of the projection of the fault plane. A geologic profile(1) at the site shows $1400 \mathrm{~m}$ of sandstone interbedded with clay and a few strata of marl and limestone, overlying metamorphic schist.

Compared with other strong motion records the exceptional features of the Gazli record (1) (reproduced in the september, 1977 issue of this Bulletin( $(3)$ ) are: (i) its high peak acceleration values, and (ii) the strength of the vertical accelerations, which are stronger than the horizontal accelerations throughout the period of strong shaking. The peak acceleration values recorded at Karakyr Point are $0.6 \mathrm{~g}, 0.8 \mathrm{~g}$, and $1.3 \mathrm{~g}$ in the $\mathrm{N}-\mathrm{S}, \mathrm{E}-\mathrm{W}$ and vertical components respectively; at EI Centro, 1940, horizontal peak values of $0.32 \mathrm{~g}$ and $0.21 \mathrm{~g}$ and a vertical peak of $0.21 \mathrm{~g}$ were recorded from an event with a similar magnitude $\left(M_{S}=7.1, M_{L}=6.4\right)$.

However, the differences between the vertical and horizontal components of the Gazli record, and between the Gazli and the El Centro, 1940 records are not so great when viewed in the frequency domain. Figure 2 shows smoothed Fourier amplitude spectra of the three Gazli components, again taken from reference (1), and the vertical and $\mathrm{N}-\mathrm{S}$ components of El Centro, 1940. (The spectrum of the $\mathrm{E}-\mathrm{W}$ component of the $\mathrm{EI}$ Centro record is similar to that of the $\mathrm{N}-\mathrm{S}$ component but is weaker at frequencies above $0.3 \mathrm{~Hz}$ ). Up to a frequency of about $3 \mathrm{~Hz}$ the amplitudes of the three Gazli components are generally similar. Further, except for two minor peaks, the Gazli record is no stronger than El Centro N-S in the middle-

* Senior Lecturer in Civil Engineering, University of Canterbury. frequency band of 0.3 to $3.0 \mathrm{~Hz}$. The lower amplitude of the El Centro component at frequencies below $0.3 \mathrm{~Hz}$ is due to its marked weakness at low frequencies rather than to any abnormally high amplitudes in the Gazli record. Thus it can be seen from Figure 2 that structures with fundamental natural frequencies of below about $3 \mathrm{~Hz}$ should not be shaken more strongly in the horizontal direction by the Gazli motion than by $E 1$ Centro N-S, unless they have strong participation of higher modes.

The second unusual feature of the Gazli motion is the high strength of the vertical motions compared with the horizontal motions. Usually, vertical motions are considerably weaker than the horizontal. This is seen in the El Centro, 1940 record, in Figure 2, and on most other strong-motion accelerograms. However, the Gazli accelerogram is unique in that it was recorded within a few kilometers of the plane of a dip-slip(I) rupture. The rupture initiated at a depth of 25 to $30 \mathrm{~km}$ and presumably propagated upwards. In these circumstances Haskell (2) has shown that, neglecting the effects of the free surface, near-field vertical accelerations may be of the order of twice the magnitude of the horizontal accelerations.

The strong amplitudes at high frequencies in all three components of the Gazli record are also unusual and are probably the result of several different factors. However, it is likely that the proximity of the recording site to the fault is the principal cause. The high frequency components, which decay at a much greater rate than low frequency components, would have undergone little attenuation over such short distances.

A further point to note in comparing the Gazli and EI Centro records is the failure of peak ground acceleration values to characterize the strength of ground shaking in the middle frequency band, which is the one of most interest to earthquake engineers. The usefulness of a spectral characterization of ground motion is clear from Figure 2 which shows that while the $\mathrm{El}$ Centro N-S motion is similar to or slightly stronger than the Gazli vertical motion in the 0.3 to $3 \mathrm{~Hz}$ band, the Gazli component has a peak ground acceleration value of four times that of the El Centro component. This comparison illustrates quite clearly one of the principal shortcomings of peak ground acceleration as a single-parameter measure of ground motion; namely that it characterizes only the high frequency components of motion, say those above about 3 to $5 \mathrm{~Hz}$.

These preliminary conclusions may be summed up as follows:

(1) The high peak accelerations recorded 
at Karakyr Point are the result of strong components of motion at frequencies of $3 \mathrm{~Hz}$ and higher.

(2) In the middle-frequency band of 0.3 to $3 \mathrm{~Hz}$, the ground shaking at Karakyr Point was about as strong as the $\mathrm{N}-\mathrm{S}$ horizontal motion at El Centro, 1940.

(3) The relatively high strength of the vertical components is consistent with the reportedly dip-slip mechanism of the earthquake.

\section{REFERENCES}

1. Pletnev, K. G., Shebalin, N. V. and

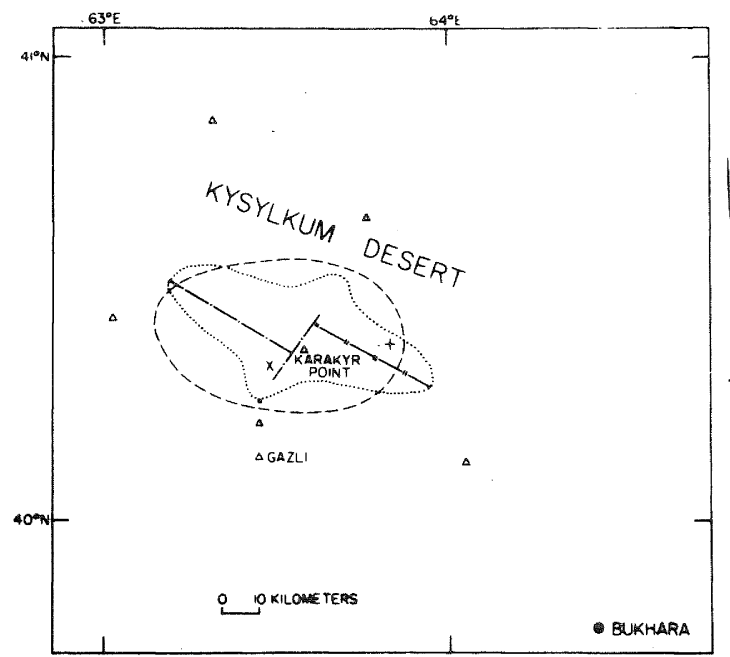

FIGURE 1: THE EPICENTRAL REGION OF THE GAZLI EARTHQUAKES, SHOWING THE LOCATION OF THE KARAKYR POINT STRONG-MOTION ACCELOGRAPH (FROM REFERENCE 1).

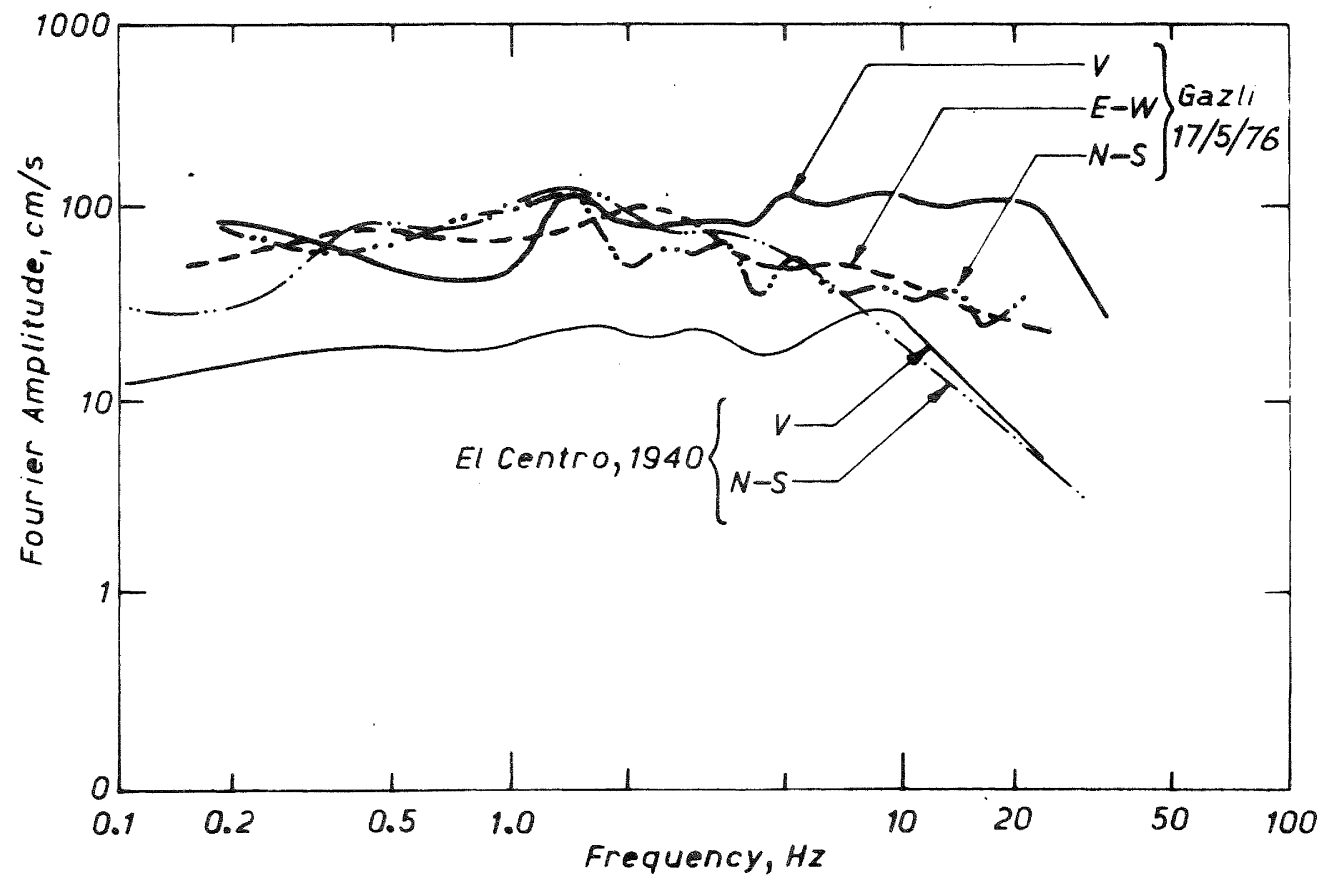

FIGURE 2: HAND -SMOOTHED FOURIER AMPLITUDE OF ACCELERATION SPECTRA FOR THE GAZLI, USSR \& EL CENTRO, 1940 ACCELOGRAMS Earthquakes": U.S. Geol. Survey
Shteinberg, V. V., "Strong-Motion Records from the May 1976 Gazli, U.S.S.R.

2. Haskell, N. A., "Elastic Displacements in the Near-Field of a Propagating Fault", Bull. Seism. Soc. Am., 59, 2, 865-908, 1969.

3. Gazli Earthquake Note. Information Section of Bulletin of N.Z. National Society for Earthquake Engineering. Vol. 10, No. 3 September, 1977.

\section{EXPLANATION}

+ April 8.1976 earthquake epicenter

$\times$ Moy 17, 1976 earthquake epicenter

Probable foult plone of $A$ pril 8,1976 earthauake

Probabie foult plane of May 17, 1976 earthquake

Aftershock areo

Intensity IX isoseismal (approximate) 